\title{
SUSCEPTIBILIDADE À FADIGA TÉRMICA DE MATRIZES FECHADAS PARA FORJAMENTO A QUENTE
}

\author{
Frederico de Castro Magalhães \\ Roberto Braga Figueiredo ${ }^{2}$ \\ Maria Teresa Paulino Aguilar ${ }^{3}$ \\ Antônio Eustáquio de Melo Pertence ${ }^{4}$ \\ Haroldo Béria Campos ${ }^{5}$ \\ Paulo Roberto Cetlin ${ }^{6}$
}

\section{Resumo}

As forjarias vem procurando, constantemente, aços ferramentas que proporcionem um melhor rendimento produtivo, por meio da maximização da vida útil das matrizes, reduzindo assim, os custos de produção. Essa vida útil é expressa pelo número de peças forjadas (ciclo de produção), antes de ser rejeitadas pela presença de algum mecanismo de falha, que venha alterar as dimensões e/ou a geometria do produto final ou até mesmo ocasionar a quebra das matrizes. Dentre esses mecanismos destaca-se a fadiga térmica, ocasionada pelo aquecimento e resfriamento cíclicos a que as matrizes são submetidas. Baseado no estudo de Maim e Norstrom [I], este trabalho teve como objetivo desenvolver uma sub-rotina para o aplicativo numérico DEFORM 2D, que utiliza o método dos elementos finitos, capaz de prever regiões propícias a fadiga térmica. A modelagem numérica empregando coeficientes adequados para os fenômenos de transmissão de calor levou a resultados semelhantes aos experimentais, permitindo a validação da sub-rotina proposta. Palavras-chave: Forjamento a quente; Fadiga térmica; Elementos finitos; Aço HI3.

\section{SUSCEPTOBILITY TO THERMAL FATIGUE OF CLOSED DIE HOT FORGING DIES}

\begin{abstract}
Hot forging dies providing high productive performance reduce production costs. The lifetime of the dies is expressed by the number of forgings (production cycle) produced before being rejected by the presence of a failure mechanism, associated with unacceptable dimensions and or geometry of the end product or even breakage of the dies. One of the failure mechanisms of hot forging dies is thermal fatigue, caused by cyclic heating and cooling. A subroutine, based on the work of Maim and Norstrom [I], was developed for the DEFORM 2D numerical software, using the finite element method, in order to predict die regions susceptible to thermal fatigue. The use of adequate coefficients for the description of the heat transfer phenomena allowed the validation of the proposed subroutine.
\end{abstract}

Keywords: Hot forging; Thermal fatigue; Finite elements; HI 3 steel.

\footnotetext{
'Engenheiro Mecânico, Doutor, Consultor técnico, Belo Horizonte, MG, Brasil. E-mail: fredmag@br.inter.net

${ }^{2}$ Engenheiro Mecânico, Doutor, Professor Adjunto, Departamento de Engenharia de Materiais e da Construção Civil, Universidade Federal de Minas Gerais - UFMG, Belo Horizonte, MG, Brasil. E-mail: roberto-rb@ufmg.br

${ }^{3}$ Engenheira Metalurgista, Doutora, Professora Titular, Departamento de Engenharia de Materiais e da Construção Civil, Universidade Federal de Minas Gerais - UFMG, Belo Horizonte, MG, Brasil. E-mail: teresa@ufmg.br

${ }^{4}$ Engenheiro Mecânico, Doutor, Professor Associado, Departamento de Engenharia Mecânica, Universidade Federal de Minas Gerais - UFMG, Belo Horizonte, MG, Brasil. E-mail: pertence@ufmg.br

${ }^{5}$ Físico, Doutor, Professor Associado, Departamento de Engenharia Mecânica, Universidade Federal de Minas Gerais - UFMG, Belo Horizonte, MG, Brasil.E-mail: Haroldo@demec.ufmg.br

${ }^{6}$ Engenheiro Mecânico, Doutor, Professor Titular, Departamento de Engenharia Mecânica, Universidade Federal de Minas Gerais - UFMG, Belo

Horizonte, MG, Brasil. E-mail: pcetlin@demec.ufmg.br
} 


\section{INTRODUÇÃO}

Os produtos metálicos semiacabados são caracterizados por não apresentarem a forma final, e são fabricados por meio de processos tais como laminação, forjamento, extrusão e trefilação. Para o processo de forjamento a quente, frequentemente utiliza-se como matéria-prima aços carbonos e ligados e para as matrizes os aços ferramenta AISI HII, HI2 e HI3, sendo o AISI HI3 um dos mais utilizados [2]. Os produtos forjados apresentam uma boa resistência mecânica e certa precisão dimensional [3] e são empregados, largamente, na indústria petroquímica, mecânica e automobilística. Em 20I I, a produção mundial de produtos forjados a quente foi de 4 milhões de toneladas [4]. A Figura I mostra uma conexão semiacabada destinada à indústria petroquímica.

As forjarias exigem alto rendimento produtivo por meio da maximização da vida útil das matrizes e assim, reduzindo os custos de produção. Essa vida útil é comumente expressa pelo número de peças forjadas (ciclos de produção), antes da rejeição das matrizes devido a algum tipo de falha que venha alterar as dimensões e/ou a geometria do produto final ou até mesmo pela quebra das matrizes. Entre os mecanismos de falha presente em uma matriz de forjamento a quente, destacam-se: fadiga mecânica, fadiga térmica, deformação plástica e desgaste por abrasão. A Figura 2 retrata possíveis regiões onde estes mecanismos de falha podem atuar [3].

Durante a sua vida útil, as matrizes de forjamento a quente são submetidas a aquecimentos e resfriamentos cíclicos que geram tensões térmicas, propiciando a formação de fissuras que tem origem na superfície das matrizes. A Figura 3 apresenta o aspecto típico da malha de trincas térmicas na superfície de uma matriz de aço $\mathrm{HI}$, destinada ao forjamento em prensas excêntricas [5]. A literatura apresenta que $o$ início das trincas térmicas ocorre em média a menos de $1 \%$ da vida útil do ferramental [6].

No campo geral da fadiga de baixo ciclo (< 1.000 ciclos), onde as deformações plásticas em cada ciclo excedem as deformações elásticas, podem-se considerar duas categorias: térmica, se a temperatura não é constante com o tempo e isotérmica, se a temperatura é constante ao longo do tempo [7].

Segundo Spera e Mowbray [7] a fadiga térmica é definida como a deterioração gradual dos materiais que sofrem aquecimentos e resfriamentos alternados, durante os quais a expansão térmica é parcial ou completamente restringida. Esta restrição origina tensões térmicas que podem provocar a iniciação e propagação de fissuras nas superfícies das matrizes. A severidade dos ciclos térmicos é determinada principalmente, pela diferença de temperatura, pela temperatura máxima atingida e pelas velocidades de aquecimento e resfriamento. As fissuras térmicas tendem a se desenvolver em regiões nas quais não se têm nenhum tipo de concentrador de tensão.

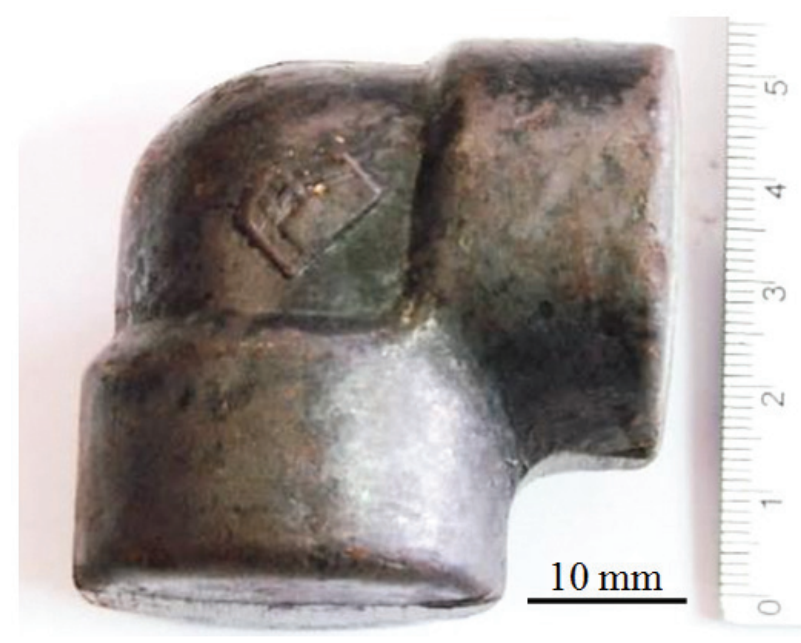

Figura I. Conexão semiacabada forjada a quente.

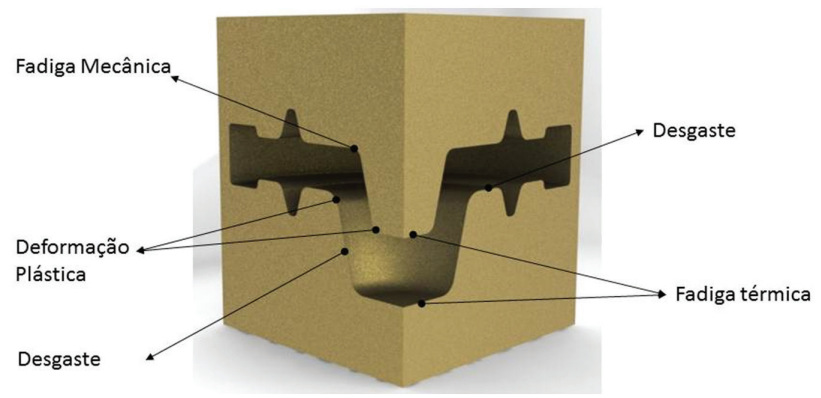

Figura 2. Mecanismos de falhas presentes na ferramenta de forjamento a quente.

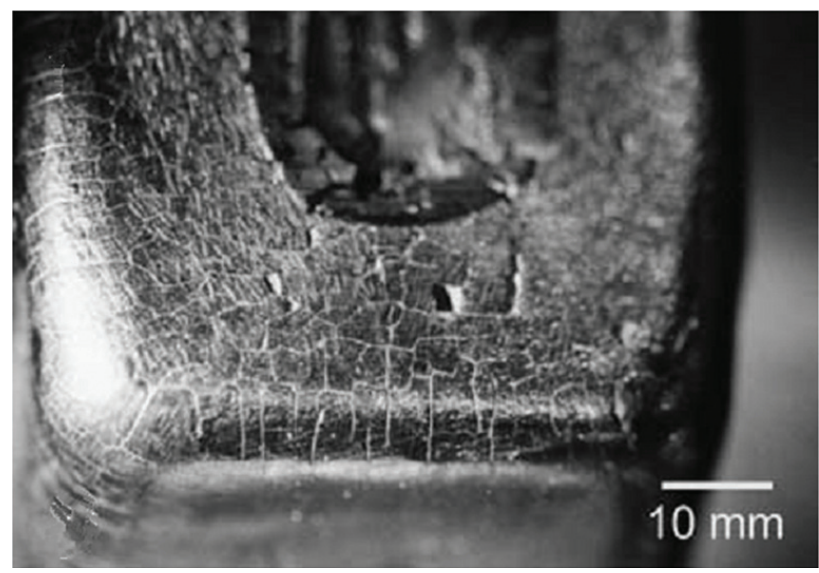

Figura 3. Malha de trincas térmicas observadas na matriz de forjamento a quente [4].

De acordo com os estudos de Maim e Norstrom [I], para que ocorra a fadiga térmica de baixo ciclo, a amplitude da deformação térmica deve exceder a deformação elástica, que pode ser expressa pela Equação I:

$$
\alpha\left(T_{2}-T_{1}\right)>2 \frac{\left(I-v_{2}\right) \sigma_{2}}{E_{2}}+2 \frac{\left(I-v_{1}\right) \sigma_{1}}{E_{1}}
$$


onde $\alpha$ é o coeficiente médio da expansão térmica, $v_{1}$ e $v_{2}$ são os coeficientes de Poisson, $\sigma_{2}$ e $\sigma_{1}$ são as tensões e $E_{1}$ e $E_{2}$ são os módulos de elasticidade para as temperaturas mínimas $\left(T_{1}\right)$ e máximas $\left(T_{2}\right)$ respectivamente.

Existem poucos estudos experimentais e numéricos que objetivam determinar o número de ciclos de produção das matrizes em relação à fadiga térmica, principalmente para aplicações específicas, como o uso do aço AISI HI 3 no forjamento a quente. Entre os estudos experimentais já realizados, destaca-se o já mencionado trabalho de Maim e Norstrom [I], que visa o desenvolvimento e aplicação de modelos matemáticos específicos para os aços ferramenta, com o objetivo de simplificar o entendimento prático das tensões e deformações envolvidas no processo de conformação a quente. Neste trabalho foi desenvolvida uma sub-rotina para o aplicativo numérico DEFORM 2D, capaz de prever regiões propícias à fadiga térmica em uma matriz de corpos moedores. Os resultados numéricos foram comparados com os resultados industriais para a validação da sub-rotina proposta.

\section{MATERIAIS E MÉTODOS}

Para a previsão das regiões propícias à fadiga térmica em uma matriz de corpos moedores, foi inicialmente desenvolvida uma simulação utilizando o aplicativo numérico DEFORM 2D. Posteriormente os resultados foram validados a partir de dados industriais.

\section{I Materiais}

A Figura 4 mostra o ferramental construído para o forjamento a quente de corpos moedores esféricos com diâmetro nominal de $90 \mathrm{~mm}$, prevendo-se a formação de rebarba entre as matrizes. Tanto o canal quanto a garganta de rebarba seguem a norma DIN [8] (Figura 5). Para assegurar o exato posicionamento e evitar um possível deslocamento relativo horizontal das matrizes superior e inferior foram utilizados pinos-guia, indicados na Figura 4.

O material utilizado para as matrizes foi o aço ferramenta AISI HI3, que apresentou uma dureza média de 52 HRC depois de temperado e revenido. Para os corpos moedores foi usado o aço carbono AISI 1045. As Tabelas I e 2 mostram a composição química do aço ferramenta AISI HI 3 e do aço carbono AISI 1045.

De acordo com Grunning [9], a fim de evitar a flambagem, a altura do tarugo não deve exceder a 2,5 vezes o seu diâmetro. Assim sendo, foi utilizado um tarugo cilíndrico, no aço carbono AISI 1045, com diâmetro de $76,2 \mathrm{~mm}$ e altura de $120 \mathrm{~mm}$, aquecido em um forno de indução a uma temperatura média de $950^{\circ} \mathrm{C}$. Esse mesmo tarugo foi posicionado em pé, apoiado na matriz inferior, que foi pré-aquecida juntamente com a matriz superior a $200^{\circ} \mathrm{C}$, temperatura recomendada para o forjamento do aço carbono. $O$ aquecimento das matrizes foi realizado por meio de aquecedores a gás (GLP). Para o monitoramento das temperaturas do tarugo e das matrizes foi empregado um termômetro digital do tipo K. O tempo total ou ciclo de operação foi de 20 segundos, considerando o transporte do tarugo para a prensa mecânica, seu posicionamento, sua conformação, a retirada do produto final e da aplicação do desmoldante a base de grafite. Ressalta-se que a aplicação do desmoldante se deu entre um intervalo de um corpo moedor forjado.

\subsection{Método dos Elementos Finitos}

O aplicativo numérico DEFORM 2D (SFTC - Scientific Forming Technologies, Ohio, USA), empregado para simular o ciclo de forjamento dos corpos moedores, utiliza a formulação implícita de integração no tempo, onde a solução da equação de governo que rege o equilíbrio é obtida pela consideração no tempo $\mathrm{t}+\mathrm{dt}$. Para determinar

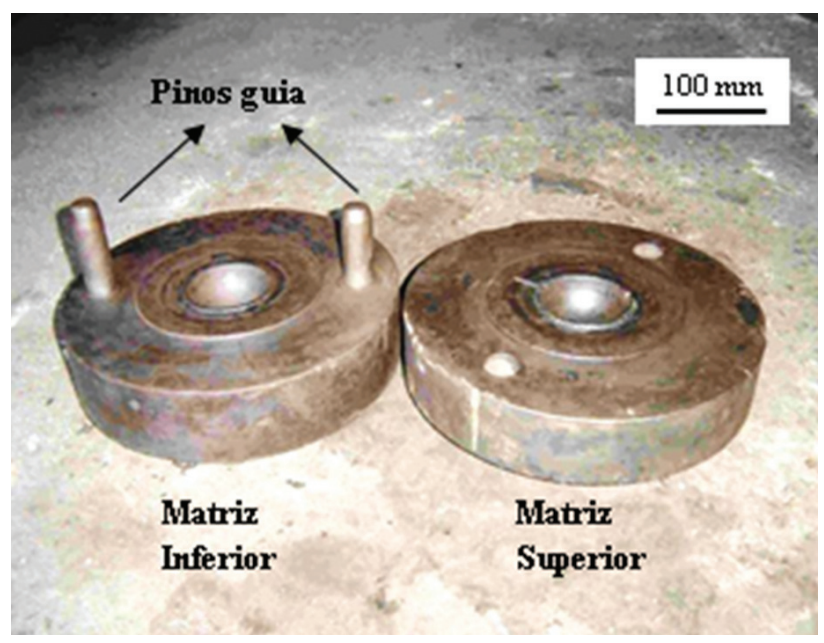

Figura 4. Matriz superior e inferior empregadas no forjamento dos corpos moedores.

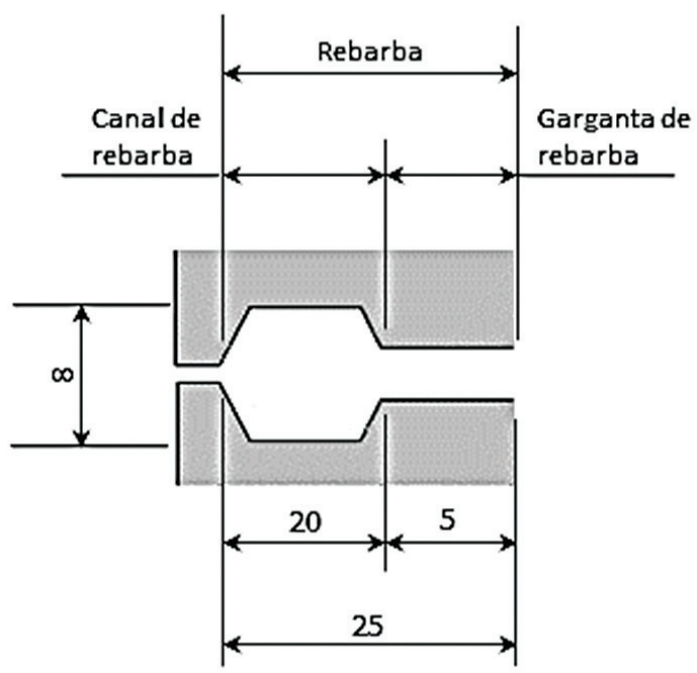

Figura 5. Geometria do canal e dimensões da bacia de rebarba (medidas em $\mathrm{mm}$ ). 
Tabela I. Composição química do aço ferramenta AISI HI 3 empregado para a confecção das matrizes (\% em peso)

\begin{tabular}{cccccc}
\hline$\% \mathbf{C}$ & $\% \mathbf{M n}$ & $\% \mathbf{S i}$ & $\% \mathbf{C r}$ & $\% \mathbf{M o}$ & $\% \mathbf{V}$ \\
\hline 0,36 & 0,40 & 1,10 & 5,20 & 1,50 & 0,90 \\
\hline
\end{tabular}

Tabela 2. Composição química do aço carbono AISI 1045 empregado para a confecção dos corpos moedores (\% em peso)

\begin{tabular}{cccccc}
\hline$\% \mathbf{C}$ & $\% \mathbf{M n}$ & $\% \mathbf{S i}$ & $\% \mathbf{S}$ & $\% \mathbf{P}$ & $\% \mathbf{C r}$ \\
\hline 0,46 & 0,72 & 0,23 & 0,021 & 0,015 & 0,05 \\
\hline
\end{tabular}

possíveis regiões propícias à fadiga térmica de baixo ciclo por meio da Equação I, durante o estado estacionário de temperatura, fez-se necessário a implementação de uma sub-rotina.

Em virtude das matrizes superior e inferior e do material a ser forjado apresentarem geometrias de revolução em torno de um mesmo eixo, o conjunto matrizes/ material foi reduzido a um estado de deformação axissimétrica (Figura 6).

O aço AISI 1045 foi modelado como material isotrópico e rígido-plástico, com uma malha de 1.000 elementos quadrados, conforme a Figura 5. Para evitar a remalha automática do tarugo, que pode comprometer os resultados numéricos, decidiu-se que a malha seria mais densa no lado voltado para a bacia de rebarba (elementos com 0,2 mm). A curva de fluxo para descrever o comportamento do aço carbono AISI 1045 durante os ciclos de forjamento é função da deformação, da taxa de deformação e da temperatura $\sigma_{\text {ef }}=\sigma\left(\varepsilon_{e f}, \dot{\varepsilon}_{e f}, T\right)$ e suas propriedades mecânicas e térmicas foram obtidas diretamente da biblioteca do aplicativo numérico. As matrizes superior e inferior também foram modeladas como materiais isotrópicos e elásticos. A malha é mais densa, com elementos com 0,2 mm, na região de contato com o material a ser forjado, garantindo assim, boa convergência dos resultados. Uma malha mais grosseira, (elementos com I mm), foi empregada no restante das matrizes, sem comprometer os resultados. Foi utilizado um fator de atrito de 0,3 nas interfaces das matrizes/material [10].

\subsection{Transferência de Calor e Parâmetros Térmicos}

A evolução térmica do material e das matrizes, no processo de forjamento a quente, envolve a geração de calor causada pela deformação plástica do material, pelo atrito material/ferramenta e pela dissipação de calor por transmissão ao meio ambiente.

Empregou-se $\circ$ valor de $25^{\circ} \mathrm{C}$ para descrever a temperatura ambiente e a solução grafitada. Os parâmetros térmicos dos materiais foram retirados da biblioteca do aplicativo numérico e na falta de alguma propriedade, essa foi obtida dos trabalhos de Chun [II] e Sjöström [6]. Durante o forjamento e o resfriamento das matrizes foram empregados os seguintes coeficientes de transferência de calor:

- Forjamento

Matriz/Tarugo: $15 \mathrm{~kW} \cdot \mathrm{m}^{-2} \cdot \mathrm{K}^{-1}$ e Matriz/Matriz: II kW.m ${ }^{-2} \cdot \mathrm{K}^{-1}$

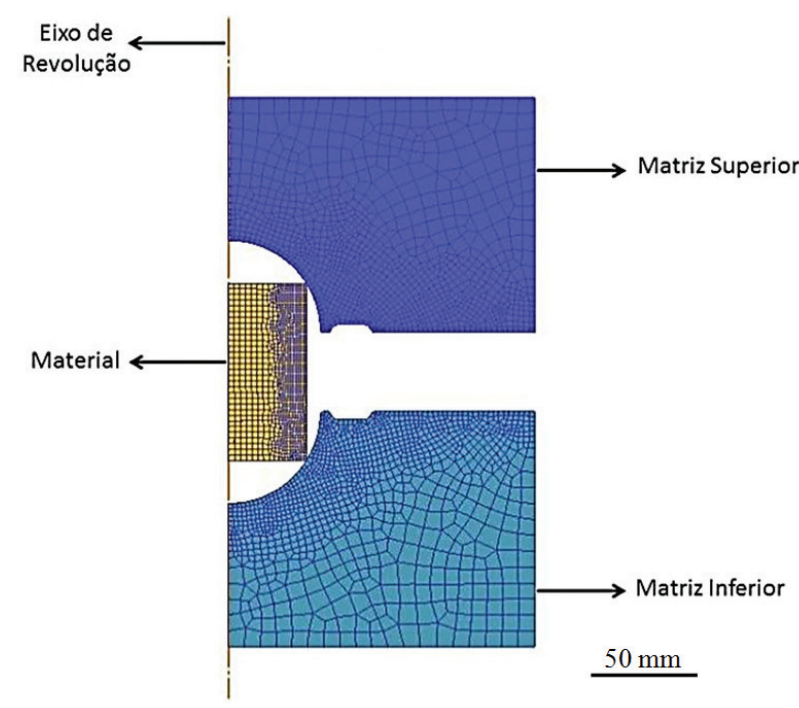

Figura 6. Modelagem numérica do conjunto.

- Resfriamento

Matriz/Matriz: II kW. $\mathrm{m}^{-2} \cdot \mathrm{K}^{-1}$ e Face em contato com desmoldante: $45 \mathrm{~kW} \cdot \mathrm{m}^{-2} \cdot \mathrm{K}^{-1}$

\subsection{Estado Estacionário de Temperatura e Sub-rotina}

Para descrever o estado estacionário de temperatura, foram avaliadas numericamente as evoluções das temperaturas, em ciclos sucessivos de forjamento, nos três pontos destacados na matriz inferior, Figura 7. Estes pontos foram escolhidos uma vez que as temperaturas máximas ocorrem na superfície da cavidade da matriz. $\mathrm{O}$ ponto $\mathrm{PI}$ encontra-se na borda superior da cavidade, P2 no ponto de contato entre material/matriz e P3 no ponto mais baixo da cavidade. Ressalta-se que as condições térmicas do ciclo anterior forram transferidas para o ciclo posterior de forjamento, no intuito de se obter esse estado. As simulações numéricas em que envolveram o uso do desmoldante foram baseadas nos estudos de Chun [II].

Uma vez obtido o estado estacionário da temperatura, os módulos de elasticidade, os coeficientes de Poisson e as tensões referentes às temperaturas máximas e mínimas, foram introduzidos na sub-rotina, determinando assim, regiões sujeitas à fadiga térmica, Equação $I$. As propriedades mecânicas e térmicas do aço $\mathrm{HI} 3$ eram 
retiradas do aplicativo numérico e dos trabalhos de Chun [I I] e Sjöström [6].

A Figura 8 mostra a representação esquemática do algoritmo usado no projeto da sub-rotina.

\section{RESULTADOS}

As simulações numéricas mostraram que ciclo estacionário das temperaturas nos pontos $\mathrm{PI}, \mathrm{P} 2$ e $\mathrm{P} 3$ teve início após a $66^{\mathrm{a}}$ peça forjada. O gráfico da Figura 9 mostra as evoluções das temperaturas nos estados estacionários

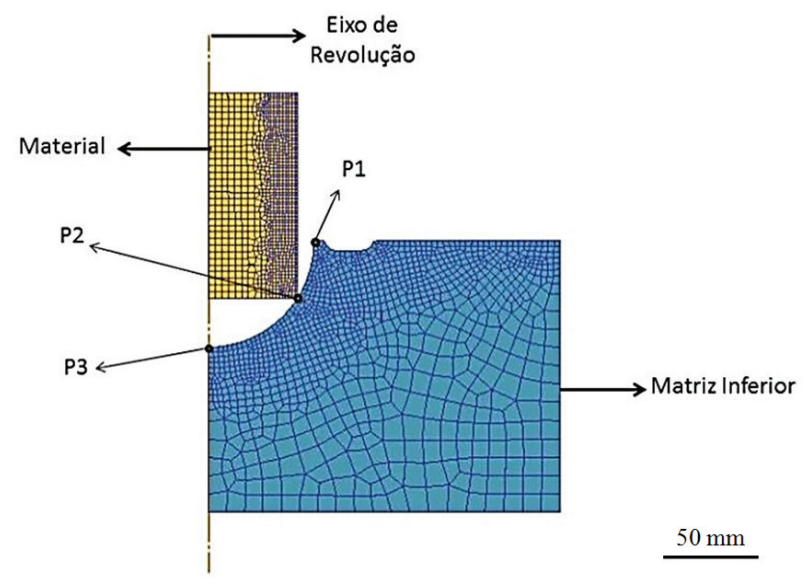

Figura 7. Pontos escolhidos para avalição do gradiente térmico na matriz inferior.

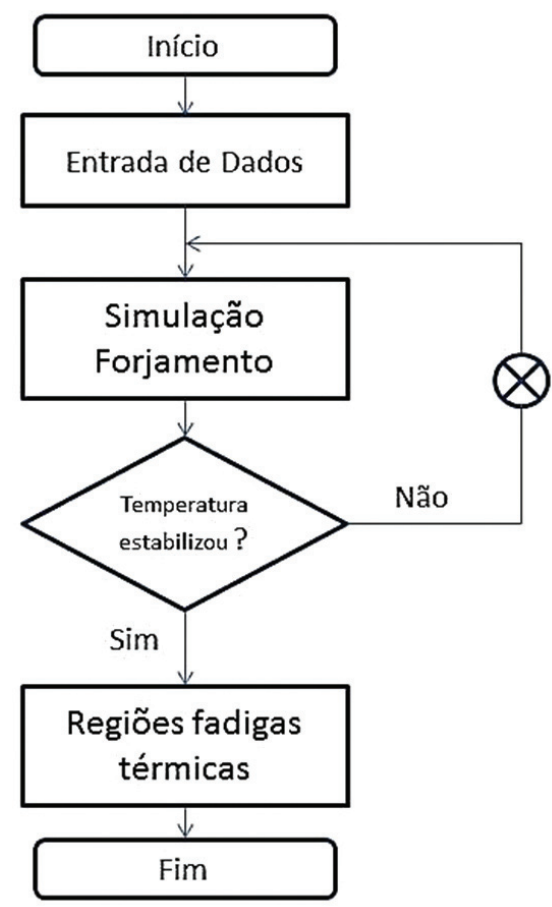

Figura 8. Fluxograma do algoritmo implementado no aplicativo numérico DEFORM 2D. para esses pontos no $67^{\circ}$ ciclo de forjamento e as médias das máximas temperaturas medidas industrialmente nos respectivos pontos.

Tanto no início ( 1.320 segundos) quanto no final do ciclo de forjamento ( 1.340 segundos), as temperaturas nos pontos $\mathrm{PI}$ e $\mathrm{P} 2$ foram semelhantes. A não existência de contato com o tarugo nos instantes iniciais do processo de forjamento do corpo moedor faz com que as temperaturas nos pontos $\mathrm{PI}$ e $\mathrm{P} 3$ permaneçam constantes, ao contrário do ponto $\mathrm{P} 2$, que representa o ponto de apoio do tarugo com a matriz, onde a temperatura aumenta de forma gradativa de $260^{\circ} \mathrm{C}$ até $560^{\circ} \mathrm{C}\left(\Delta \mathrm{T}=300^{\circ} \mathrm{C}\right)$. Quando se inicia a formação de rebarba devido ao preenchimento total da cavidade da matriz, as temperaturas nos pontos $\mathrm{PI}$ e $\mathrm{P} 3$ apresentam um aumento significativo de $465^{\circ} \mathrm{C}$ e $280^{\circ} \mathrm{C}$ respectivamente. Após a conformação do tarugo, I.328 segundos, fez-se a aplicação do desmoldante por dois segundos. Durante a aplicação do desmoldante, as temperaturas nos três pontos escolhidos decaem rapidamente, e uma vez terminada a sua aplicação, o decaimento torna-se mais suave. Este mesmo comportamento foi observado por Chun [I I].

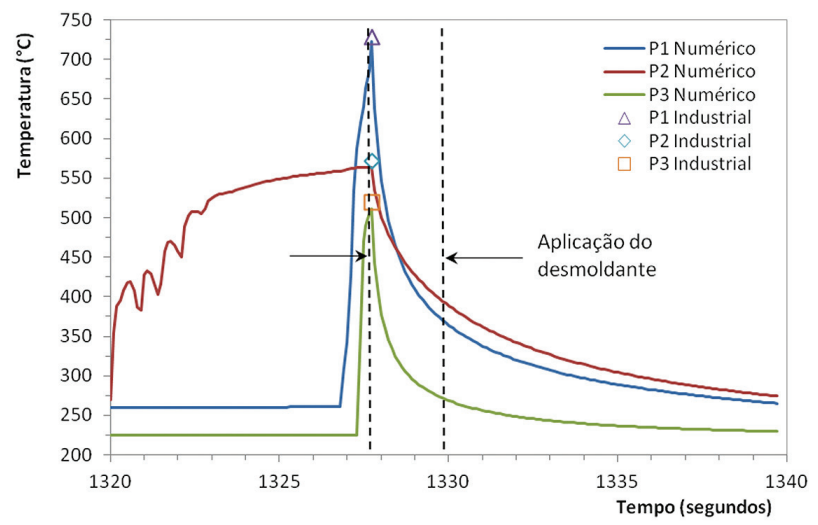

Figura 9. Perfis térmicos dos pontos $\mathrm{PI}, \mathrm{P} 2$ e $\mathrm{P} 3$ no $67^{\circ}$ ciclo de forjamento e as máximas temperaturas industriais.

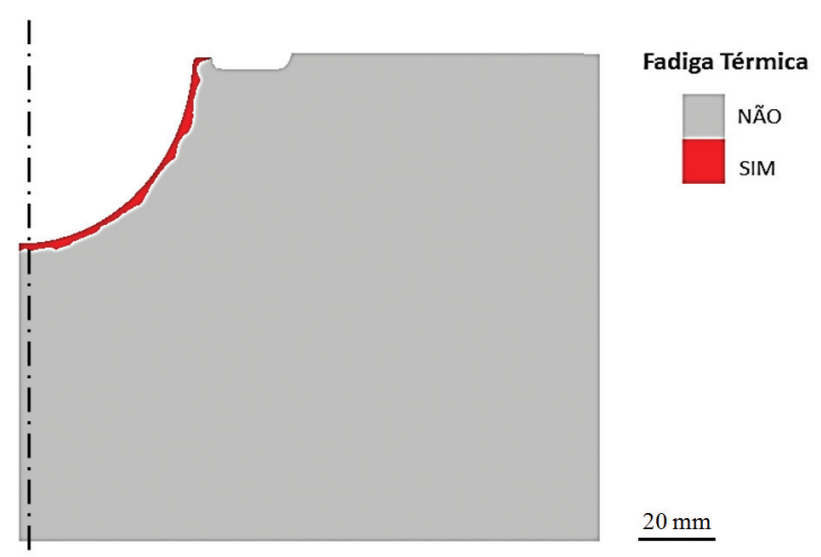

Figura 10. Mapeamento das áreas sujeitas à fadiga térmica obtida pela sub-rotina. 


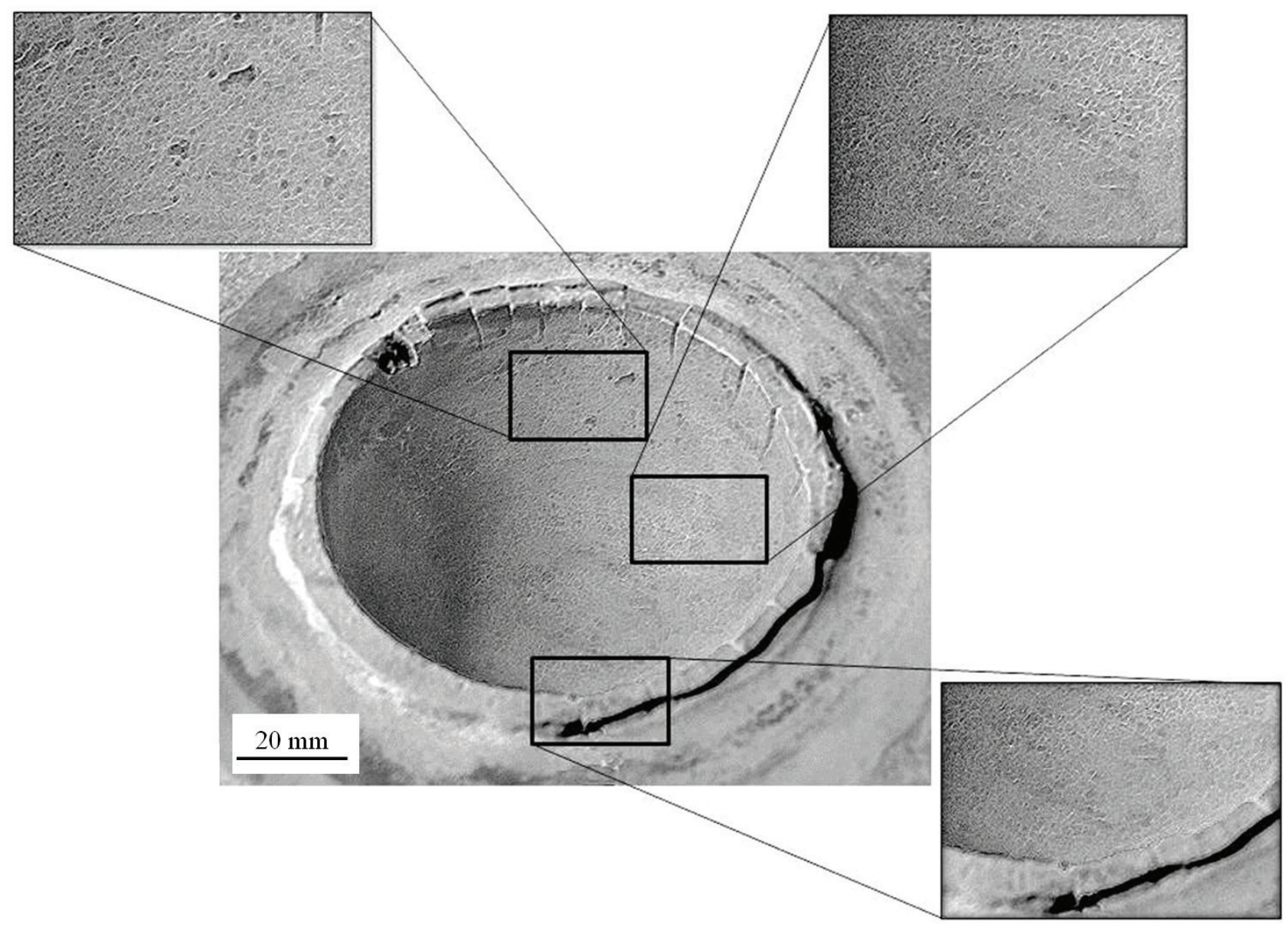

Figura I I. Fadigas térmicas observadas ao longo da cavidade da matriz inferior após 950 ciclos de forjamento.

Por apresentar a maior temperatura no decorrer do processo $\left(722^{\circ} \mathrm{C}\right)$, o ponto $\mathrm{PI}$ pode desenvolver outro possível mecanismo de falha, a deformação plástica, que está associada à queda do limite de escoamento do material (AISI HI3), capaz de alterar as dimensões do produto final nesta região.

A modelagem indicou que as regiões onde ocorrem as maiores variações térmicas são favoráveis ao desenvolvimento da fadiga térmica (cavidade da matriz, cor vermelha, Figura 10 ), de acordo com o observado nas matrizes dos corpos moedores, Figura II, e no trabalho de Sjöström [6].

\section{CONCLUSÕES}

Os valores dos coeficientes de transferência de calor empregados nas simulações numéricas, para determinar as evoluções das temperaturas nos ciclos de forjamento, geraram resultados condizentes com os que foram obtidos industrialmente.

A cavidade da matriz, por estar sujeita aos maiores gradientes térmicos, é propícia ao desenvolvimento das fissuras térmicas, fato comprovado industrialmente e pelos resultados numéricos obtidos pela sub-rotina implantada no aplicativo DEFORM 2D.

A sub-rotina implementada no aplicativo DEFORM $2 D$, para simulação numérica do forjamento a quente de corpos moedores, revelou-se uma ferramenta de interesse na avaliação da vida útil das matrizes empregadas no processo.

\section{Agradecimentos}

Os autores agradecem a Capes, ao CNPq e a Fapemig pelo suporte para a concretização deste trabalho. 


\section{REFERÊNCIAS}

I Maim S, Norstrom LA. Material-related model for thermal fatigue applied to tool steels in hot-work applications. Metal Science. 1979; I3(9):544-50. http://dx.doi.org/I0.I I 79/03063457979043829 I

2 Stahlinstitut. Stahl eisen liste (Hrsg-VDEh) 9. Dusseldorf: Verlag Sthaleissen; 1998.

3 Konig W, Klocke F. Fertigungsverfahren. Bd. 4. Massivumformung. Dusseldorf: VDI-verlag; 2006.

4 Witt S. Basic knowledge - forgings: significance, design, production, application. 2012 [acesso em $10 \mathrm{abr} 2014$ ]. Disponível em: http://www.euroforge.org/fileadmin/user_upload/eLibrary/IMU_Basic_Knowledge_English_final_ I 03-I4.pdf.

5 Sjöström J, Bergström J. Thermal fatigue in hot-working tools. Scand. J. Metall. 2005;34:22I-3I. http://dx.doi. org/I0.1III/j.1600-0692.2005.007/9.x

6 Sjöström J. Chromium martensitic hot-work tool steels [dissertação]. Karlstad: Karlstad University Studies; 2004.

7 Spera DA, Mowbray DF. ASTM-STP6 I2: Thermal fatigue of materials and components. ASTM; 1976. What is thermal fatigue; p. 3-9.

8 Lange K. Umformtechnik. Bd.2, Massivumformung. Berlin: Springer-Verlag; 1998. PMid:9667935.

9 Grunning K. Técnica da Conformação. São Paulo: Editora Polígono SA; 1996. p. 38-64.

10 Semiatin SL. ASM Handbook, Vol. 14 A: Metalworking: Bulk Forming. Materials Park: ASM International; 2005.

I I Chun L. Modeling of water and lubricant sprays in hot metal working [dissertação]. Ohio: State University; 2007.

Recebido em: $21 / 10 / 2013$

Aceito em: 26/3/20I4 